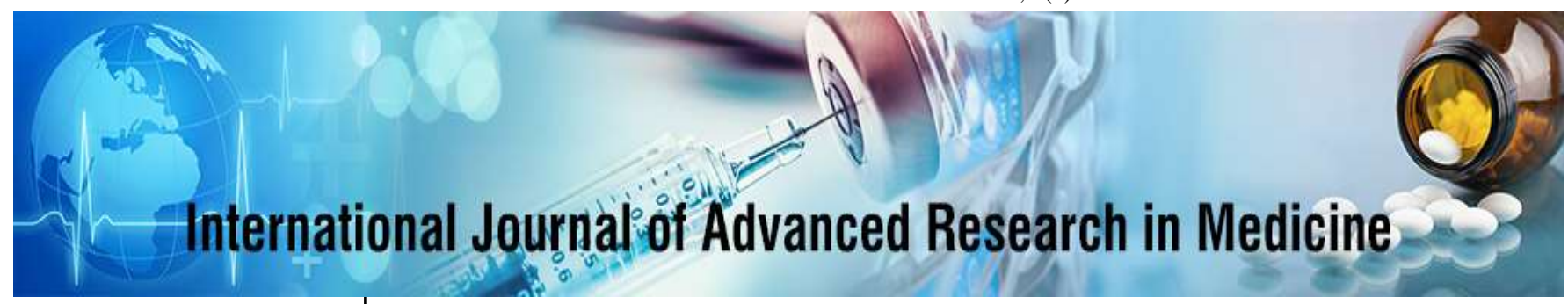

E-ISSN: 2706-9575

P-ISSN: 2706-9567

IJARM 2021; 3(1): 286-288

Received: 18-12-2020

Accepted: 08-02-2021

\section{Majid Farooq}

Department of Pharmacology,

Sher-i-Kashmir Institute of

Medical Sciences Medical

College, Bemina, Srinagar,

Jammu \& Kashmir, India

\section{Anna Javed}

Department of Pharmacology,

Sher-i-Kashmir Institute of

Medical Sciences Medical

College, Bemina, Srinagar,

Jammu \& Kashmir, India

\section{Parveen Gupta}

Professor, Department of

Medicine, Maharishi

Markandeshwar Institute of

Medical Sciences and Research,

Mullana, Ambala, Haryana,

India
Corresponding Author: Majid Farooq Department of Pharmacology, Sher-i-Kashmir Institute of Medical Sciences Medical College, Bemina, Srinagar, Jammu \& Kashmir, India

\section{A comparative assessment of propranolol, flunarizine and divalproex sodium in prophylactic therapy of migraine in a teaching Hospital in North India}

\author{
Majid Farooq, Anna Javed and Parveen Gupta
}

DOI: https://doi.org/10.22271/27069567.2021.v3.i1e.154

\begin{abstract}
Background: Migraine is one of the oldest, debilitating ailments known to man and is characterized by recurring, frequent, unilateral headaches lasting between 4 and 72 hours, aggravated by routine physical activity. The present study compared propranolol, flunarizine and divalproex sodium in prophylaxis of migraine.

Materials \& Methods: 84 patients of migraine of both genders were randomly divided into 3 groups of 28 each. In group I patients received propranolol 20 to $160 \mathrm{mg} /$ day, group II patients received flunarizine 5 to $10 \mathrm{mg} /$ day and group III patients received divalproex sodium 250 to $750 \mathrm{mg} / \mathrm{day}$, for three months.

Results: There were 18 males and 10 females in group I, 15 males and 13 females in group II and 12 males and 16 females in group III. The mean frequency/month of migraine was 5.09, 5.12 and 5.02, mean duration of migraine was 20.9, 20.3 and 18.2, MIDAS was 11.9, 11.2 and 10.4 and VAS was 7.6, 6.5 and 7.2 in group I, II and III respectively. Facial swelling was seen in 2 in group II. Dizziness in 1 in group I, hair loss in 2 in group III. Tremors in 1 in group I and II and 2 in group III, weight gain in 2 in group I, 3 in group II and 5 in group III and insomnia in 1 in group II.

Conclusion: All drugs found to be equally effective in management of cases of migraine.
\end{abstract}

Keywords: Migraine, propranolol, flunarizine, divalproex sodium

\section{Introduction}

Migraine is one of the oldest, debilitating ailments known to man and is characterized by recurring, frequent, unilateral headaches lasting between 4 and 72 hours, aggravated by routine physical activity. It is often accompanied by a variety of symptoms which may be autonomic, neurological, and gastrointestinal in nature. Some of the symptoms associated with migraine are; nausea, vomiting, loss of appetite, photophobia, phonophobia, osmophobia $^{[1]}$.

Spontaneous overactivity and abnormal amplification in pain and other, predominantly sensory, pathways in the brainstem, leads to migraine. Current opinion favours a primarily neural cause, involving feedback loops through innervation of cranial arteries in the trigeminovascular system. A relative deficiency of 5-hydroxytriptamine (5-HT) may be near the root cause, and is linked to the action of most drug treatments ${ }^{[2]}$. Ongoing research is studying the relevance of calcium channel abnormalities, and peptides such as calcitonin gene related peptide, which may be closer than 5-HT to the underlying cause, offering hope for improved treatment in the future. Migraine is usually polygenic. Uncommon migraine variants, such as familial hemiplegic migraine and CADASIL, are single gene disorders. These are neurodegenerative, not primarily headache conditions ${ }^{[3]}$.

The management of migraine involves non-pharmacological and pharmacological approaches and the choice of therapy depends on the severity of the attack. The nonpharmacological therapies include avoidance of trigger factors and lifestyle modifications, while as Pharmacotherapy for primary headache disorders is traditionally divided into acute and preventive therapies ${ }^{[4]}$. The U.S. Headache Consortium and European Federation of Neurological Societies (EFNS) Task Force guidelines on the drug treatment of migraine have established the circumstances that might warrant preventive treatment ${ }^{[5]}$. The present study compared propranolol, flunarizine and divalproex sodium in prophylaxis of migraine. 


\section{Materials \& Methods}

The present study was conducted among 84 patients of migraine of both genders. All were informed regarding the study and their written consent was obtained. All had history of 3 to 12 migraines a month (IHS) for six months. Data such as name, age, gender etc. was recorded. Patients were randomly divided into 3 groups of 28 each. In group I patients received propranolol 20 to $160 \mathrm{mg} /$ day, group II patients received flunarizine 5 to $10 \mathrm{mg} /$ day and group III patients received divalproex sodium 250 to $750 \mathrm{mg} /$ day, for three months. Patients were asked for any symptoms of drowsiness or any other common adverse drug effects they felt or noticed also parameters like; Respiratory rate, weight, pulse rate, blood pressure were noted. Treatment-emergent adverse effects were recorded. Patients were allowed to use concomitant rescue medication to abort migraine attacks. Migraine Disability Assessment Score (MIDAS) and VAS was compared. Results were subjected to statistical analysis, where $\mathrm{p}$ value less than 0.05 was considered significant.

\section{Results}

Table 1: Distribution of patients

\begin{tabular}{|c|c|c|c|}
\hline Groups & Group I & Group II & Group III \\
\hline Drug & Propranolol & Flunarizine & Divalproex sodium \\
\hline M:F & $18: 10$ & $15: 13$ & $12: 16$ \\
\hline
\end{tabular}

Table I shows that there were 18 males and 10 females in group I, 15 males and 13 females in group II and 12 males and 16 females in group III.

Table 2: Comparison of parameters at the end of the study

\begin{tabular}{|c|c|c|c|c|}
\hline Parameters & Group I & Group II & Group III & P value \\
\hline Frequency/month & $-5.09 \pm 1.25$ & $-5.12 \pm 1.4$ & $-5.02 \pm 2.24$ & 0.12 \\
\hline Mean duration & $-20.9 \pm 4.46$ & $-20.3 \pm 6.5$ & $-18.2 \pm 4.68$ & 0.24 \\
\hline MIDAS & $-11.9 \pm 3.42$ & $-11.2 \pm 2.8$ & $-10.4 \pm 3.4$ & 0.15 \\
\hline VAS & $-7.6 \pm 2.25$ & $6.5 \pm 2.08$ & $-7.2 \pm 1.88$ & 0.82 \\
\hline
\end{tabular}

Table II, graph I shows that mean frequency/month of and 10.4 and VAS was 7.6, 6.5 and 7.2 in group I, II and III migraine was 5.09, 5.12 and 5.02, mean duration of migraine was 20.9, 20.3 and 18.2, MIDAS was 11.9, 11.2 respectively. The difference was non- significant $(\mathrm{P}>0.05)$.

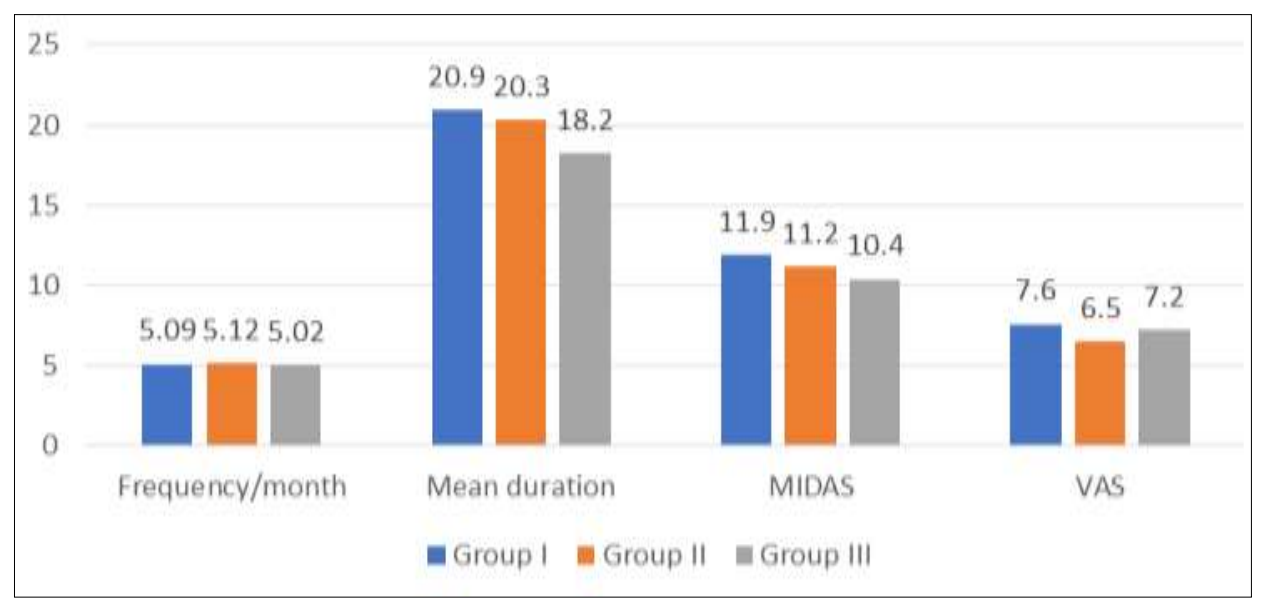

Graph 1: Comparison of parameters at the end of the study

Table 3: Adverse effects in all groups

\begin{tabular}{|c|c|c|c|c|}
\hline Adverse effects & Group I & Group II & Group III & P value \\
\hline Facial swelling & 0 & 2 & 0 & 0.14 \\
\hline Dizziness & 1 & 0 & 0 & 0.11 \\
\hline Hair loss & 0 & 0 & 2 & 0.15 \\
\hline Tremor & 1 & 1 & 2 & 0.92 \\
\hline Weight gain & 2 & 3 & 5 & 0.81 \\
\hline Insomnia & 0 & 1 & 0 & 0.11 \\
\hline
\end{tabular}

Table III shows that facial swelling was seen in 2 in group II. Dizziness in 1 in group I, hair loss in 2 in group III. Tremors in 1 in group I and II and 2 in group III, weight gain in 2 in group I, 3 in group II and 5 in group III and insomnia in 1 in group II. The difference was nonsignificant $(P>0.05)$.

\section{Discussion}

Migraine typically manifests as episodic disabling headache, though it is more than just head pain. Differential diagnosis is from tension type headache (TTH), with which migraine is co-morbid (this differential is also discussed from the other perspective elsewhere in this supplement). Migraine lasts hours or days, and is absent more often than it is present; the average attack frequency is once a month ${ }^{[6]}$. TTH is often chronic and it is present more often than it is absent. Migraine should be distinguished from cluster headache, which is relatively rare and causes recurrent unilateral headache with autonomic dysfunction ${ }^{[7]}$. The third, common though often challenging differential diagnosis is medication overuse headache $(\mathrm{MOH})$. This typically complicates migraine which is then transformed 
into a chronic daily headache similar to chronic TTH often with some migrainous features ${ }^{[8]}$.

There are two main types of migraine: migraine without aura (MO), and migraine with aura (MA). Many people have both; MO is at least three times as common as MA. Note that family history, trigger factors, and treatment response have no additional diagnostic value ${ }^{[9]}$. The present study compared propranolol, flunarizine and divalproex sodium in prophylaxis of migraine.

In present study, there were 18 males and 10 females in group I, 15 males and 13 females in group II and 12 males and 16 females in group III. In a study by Bhat et al. ${ }^{[10]}$ patients between 18 to 65 years, with history of 3 to 12 migraines a month (IHS) for six months were included. Patients were divided into three groups of 30 patients to receive - propranolol 20 to $160 \mathrm{mg} /$ day; flunarizine 5 to $10 \mathrm{mg}$ /day or divalproex sodium 250 to $750 \mathrm{mg}$ /day, for three months. Total 90/116 patients completed the study. No significant differences were found between the groups with regards to mean age or other baseline migraine features. All the drugs significantly decreased the frequency, duration and severity of migraine.

At the end of the study we found that mean frequency/month of migraine was 5.09, 5.12 and 5.02, mean duration of migraine was 20.9, 20.3 and 18.2, MIDAS was $11.9,11.2$ and 10.4 and VAS was 7.6, 6.5 and 7.2 in group I, II and III respectively. Linde M et al. ${ }^{[11]}$ in 2013, reported no significant difference in the proportion of responders between divalproex sodium versus propranolol or between sodium valproate versus flunarizine for preventing migraine attacks in adult patients with episodic migraine.

We observed that facial swelling was seen in 2 in group II. Dizziness in 1 in group I, hair loss in 2 in group III. Tremors in 1 in group I and II and 2 in group III, weight gain in 2 in group I, 3 in group II and 5 in group III and insomnia in 1 in group II. A "brain scan" is often requested by the patient or the non-specialist. Imaging may reassure and, conversely, may generate concern. Arguably, every painful head should be imaged. This would result in an impossible workload: $18 \%$ of women and $6 \%$ of men have migraine; $3 \%$ have chronic daily headache ${ }^{[12]}$. If imaged once with normal results, when should imaging be repeated? The author's experience is that about one third of UK headache patients in secondary or tertiary care are imaged, two thirds of which occurs before neurological referral. In practice it can be difficult and unhelpful to resist demand for imaging in a patient centred health care system. Magnetic resonance imaging is always preferable to computed tomography because of better resolution and lack of exposure to ionising radiation, except for emergency presentation with possible cerebral haemorrhage ${ }^{[13]}$.

Taylor FR [14] concludes that migraine preventive medications have been associated with weight gain, a higher incidence of weight gain was observed divalproex sodium than with propranolol and flunarizine.

\section{Conclusion}

Authors found that all drugs found to be equally effective in management of cases of migraine.

\section{References}

1. Vongvaivanich K. Update on Migraine Prophylaxis: Things that can help your migraine patients. The Bangkok Medical Journal 2013;5:50-60.
2. Ecsei LV, Majlath Z, Szok D, Csati A, Tajti J. Drug safety and tolerability in prophylactic migraine treatment. Expert Opin. Drug Saf 2015;14(5):1-15.

3. Weatherall MW. Drug therapy in headache. Clinical Medicine 2015;15(3):273-9.

4. Russell MB, Rasmussen BK, Brennum J. Presentation of a new instrument: the diagnostic headache diary. Cephalalgia 1992;12:369-74.

5. Leonardi M, Steiner TJ, Scher AT, Lipton RB. The global burden of migraine: measuring disability in headache disorders with WHO Classification of Functioning, Disability and Health (ICF). J Headache Pain 2005;6(6):429-40.

6. Wang SJ, Chung CS, Chankrachang S, Ravishankar K, Merican JS, Salazaret G. Migraine disability awareness campaign in Asia: migraine assessment for prophylaxis. Headache 2008;48;1356-65.

7. Silberstein SD. In: Taylor \& Francis eds. Headache in clinical practice, $2^{\text {nd }}$ Ed 2002.

8. Migraine RK. The New Understanding. Supplement of JAPI 2010;58:30-3.

9. Deleu D, Hanssens Y. Guidelines for the prevention of migraine. Neurosciences 2000;5(1):7-12.

10. Bhat MF, Sidhu HS, Goyal M. Evaluation of propranolol, flunarizine and divalproex sodium in prophylaxis of migraine. Int $\mathrm{J}$ Basic Clin Pharmacol 2017;6:2463-9.

11. Linde M, Mulleners WM, Chronicle EP, McCrory DC. Valproate (valproic acid or sodium valproate or a combination of the two) for the prophylaxis of episodic migraine in adults. Cochrane Database of Systematic Reviews. 2013;6:CD010611.

12. D' Amico D, Stewart JT. Prophylaxis of migraine: General principles and patient acceptance. Neuropsychiatric Disease and Treatment 2008;4(6):1155-67.

13. Silberstein SD. US Headache Consortium Practice parameter: evidence based guidelines for migraine headache (an evidence-based review): report of the Quality Standards Subcommittee of the American Academy of Neurology. Neurology 2000;55:754-62.

14. Taylor FR. Weight change associated with the use of migraine preventive medications. Clinical therapeutics. 2008;30(6):1069-80. 